\title{
Breeding experiments on the frequency of adjuvant arthritis in the rat
}

\author{
F. PERLÍK AND Z. ZÍDEK \\ Institute of Pharmacology, Czechoslovak Academy of Sciences, Prague 2, Czechoslovakia
}

One of the experimental approaches to the evaluation of the anti-inflammatory and/or immunosuppressive effects of drugs is the testing of their ability to suppress or inhibit adjuvant-induced arthritis in rats (AA), a widely used animal model of chronic systemic inflammation (Pearson, 1956; Newbould, 1963; Winter and Nuss, 1966). It is known that one of the factors which can influence the frequency of AA is the strain of rat used (Glenn and Gray, 1965; Swingle, Jaques, and Kvam, 1969; Currey, 1970; Rosenthale, 1970; Walz, Di Martino, and Misher, 1971). Another variable is that of the clinical symptoms of AA. Several strains of rat develop the nodular form of AA which is unlike the oedematous arthritis observed in other strains (Glenn and Gray 1965; Swingle and others 1969).

Our previous paper (Zídek and Perlik, 1971) reported graded differences in the frequency of the oedematous type of AA in five inbred strains of rat. These results suggested the theory of the multifactorial character of genetic sensitivity to the induction of AA. Variation in the frequency of AA should be regarded as 'quasi-continuous'.

The present paper is concerned with a more detailed analysis of this hypothesis, in which frequency of both types of AA (i.e. the oedematous and the nodular) is considered.

\section{Material and methods}

Three inbred strains of rat were used: Lewis $\left(P_{1}\right), A V N$ $\left(\mathrm{P}_{2}\right)$ (breeding pairs obtained from the Institute of Physiology of the Czechoslovak Academy of Sciences, Prague), and Long Evans (breeding pairs obtained from the Institute of Biology and Genetics of the Faculty of General Medicine of Charles University, Prague).

The first $\left(F_{1}=P_{1} \hat{\sigma} \times P_{2} q\right.$ and $\left.P_{2} \hat{\sigma} \times P_{1}\right)$, second $\left(F_{2}=F_{1} \times F_{1}\right)$, and both backcross $\left(B_{1}=P_{1} \times F_{1}\right.$ and $\left.B_{2}=P_{2} \times F_{1}\right)$ generations were obtained by crossing the original inbred strains, Lewis with AVN. The animals are the same as those described previously (Zídek and Perlík, 1971) but the numbers in both the inbred strains and in the $F_{1}$ generation were increased. Both sexes were included.

Accepted for publication July 6, 1972.
AA was induced in 7 to 10 -week-old animals by an intradermal injection of $0.1 \mathrm{ml}$. of an adjuvant mixture (5 mg. Mycobacterium tuberculosis/1 ml. mineral oil) into the left hind paw. Groups of rats were coded and 21 days later two distinct clinical types and their frequencies were determined according to the occurrence of signs of AA at non-injected sites (right hindleg, forepaws, ears, nose, and tail). The nodular type of AA was characterized by small subcutaneous nodules (on average of $2 \mathrm{~mm}$. in diameter), and the oedematous type by marked swelling of the joints.

For comparison, the control group of 32 untreated rats of $F_{2}$ origin was used to study a possible spontaneous occurrence of the disease.

The animals were housed four or five to a cage and allowed water and food (Velaz, Prague) ad lib. The temperature in the experimental room ranged between $19^{\circ}$ and $23^{\circ} \mathrm{C}$. and a relative humidity of 40 to 65 per cent. was maintained.

The frequency of AA in genetically homogenous generations was converted to percentiles of normal distribution according to the Tables of Fisher and Yates (1943). This procedure followed the theory of threshold characters described by Falconer (1960). It applies to a character the distribution of which is discontinuous on the visible scale but the inheritance of which is multifactorial. Therefore the involvement of a continuously varying underlying causal mechanism may be presumed. If this mechanism is unknown, then the scale of its quantification is relative, being given by percentiles of normal distribution derived from the frequencies of the trait.

\section{Results}

Marked differences were observed in the frequency of AA in the Lewis, Long Evans, and AVN strains: 100,45 , and $10 \cdot 8$ per cent. respectively (Table, opposite).

There is clearly no sex difference in the frequency of AA. Nor did the frequency between reciprocal $F_{1}$ hybrids differ $\left(\chi^{2}(1)=1 \cdot 33 ; P>0 \cdot 20\right)$. Therefore both sexes as well as reciprocals within the $F_{1}$ generation were combined for further analysis.

The incidence of AA in the generations derived from the Lewis and AVN strains differed widely. The frequency of AA in the $F_{1}$ generation does not resemble that observed in either the Lewis or the AVN strain, being approximately in the middle 
Table Frequency of AA in various groups of rats

\begin{tabular}{|c|c|c|c|c|c|c|c|c|c|c|}
\hline \multirow[t]{2}{*}{ Group } & \multirow[t]{2}{*}{ Sex } & \multirow{2}{*}{$\begin{array}{l}\text { Long } \\
\text { Evans }\end{array}$} & \multirow{2}{*}{$\begin{array}{l}\text { Lewis } \\
\left(P_{1}\right)\end{array}$} & \multirow{2}{*}{$\begin{array}{l}A V N \\
\left(P_{2}\right)\end{array}$} & \multicolumn{3}{|l|}{$F_{1}$} & \multirow[t]{2}{*}{$F_{2}$} & \multirow[t]{2}{*}{$B_{1}$} & \multirow[t]{2}{*}{$B_{2}$} \\
\hline & & & & & $P_{1} \rho \times P_{2}{ }^{A}$ & $P_{2} \odot \times P_{10} \sigma^{*}$ & Total & & & \\
\hline \multirow{3}{*}{$\begin{array}{l}\text { Total number of } \\
\text { responders/ } \\
\text { number of } \\
\text { examined }\end{array}$} & $\begin{array}{l}\text { Female } \\
\text { per cent. }\end{array}$ & $\begin{array}{l}4 / 9 \\
44 \cdot 4\end{array}$ & $\begin{array}{l}25 / 25 \\
100 \cdot 0\end{array}$ & $\begin{array}{l}4 / 34 \\
11 \cdot 8\end{array}$ & $\begin{array}{l}17 / 34 \\
50.0\end{array}$ & $\begin{array}{l}12 / 18 \\
66 \cdot 7\end{array}$ & $\begin{array}{l}29 / 52 \\
55 \cdot 8\end{array}$ & $\begin{array}{l}9 / 15 \\
60 \cdot 0\end{array}$ & $\begin{array}{l}10 / 15 \\
66 \cdot 7\end{array}$ & $\begin{array}{l}5 / 15 \\
33 \cdot 3\end{array}$ \\
\hline & $\begin{array}{l}\text { Male } \\
\text { per cent. }\end{array}$ & $\begin{array}{r}5 / 11 \\
.45 \cdot 5\end{array}$ & $\begin{array}{l}40 / 40 \\
100 \cdot 0\end{array}$ & $\begin{array}{l}4 / 49 \\
8 \cdot 2\end{array}$ & $\begin{array}{l}19 / 32 \\
59 \cdot 4\end{array}$ & $\begin{array}{l}12 / 17 \\
70 \cdot 6\end{array}$ & $\begin{array}{l}31 / 49 \\
63 \cdot 3\end{array}$ & $\begin{array}{l}7 / 13 \\
53.9\end{array}$ & $\begin{array}{l}11 / 15 \\
73 \cdot 3\end{array}$ & $\begin{array}{l}8 / 15 \\
53 \cdot 3\end{array}$ \\
\hline & $\begin{array}{l}\text { Total } \\
\text { per cent. }\end{array}$ & $\begin{array}{r}9 / 20 \\
.45 \cdot 0\end{array}$ & $\begin{array}{l}65 / 65 \\
100 \cdot 0\end{array}$ & $\begin{array}{l}9 / 83 \\
10 \cdot 8\end{array}$ & $\begin{array}{l}36 / 66 \\
54 \cdot 6\end{array}$ & $\begin{array}{l}24 / 35 \\
68 \cdot 6\end{array}$ & $\begin{array}{l}60 / 101 \\
59 \cdot 4\end{array}$ & $\begin{array}{l}16 / 28 \\
57 \cdot 1\end{array}$ & $\begin{array}{l}21 / 30 \\
70 \cdot 0\end{array}$ & $\begin{array}{l}13 / 30 \\
43 \cdot 3\end{array}$ \\
\hline $\begin{array}{l}\text { Odematous respon- } \\
\text { ders/total } \\
\text { number of } \\
\text { responders }\end{array}$ & $\begin{array}{l}\text { No. } \\
\text { per cent. }\end{array}$ & $\begin{array}{l}4 / 9 \\
.44 \cdot 4\end{array}$ & $\begin{array}{l}65 / 65 \\
100 \cdot 0\end{array}$ & $\begin{array}{l}3 / 9 \\
33 \cdot 3\end{array}$ & $\begin{array}{l}20 / 36 \\
55 \cdot 6\end{array}$ & $\begin{array}{l}17 / 24 \\
70 \cdot 8\end{array}$ & $\begin{array}{l}37 / 60 \\
61 \cdot 7\end{array}$ & $\begin{array}{l}10 / 16 \\
62 \cdot 5\end{array}$ & $\begin{array}{l}20 / 21 \\
95 \cdot 2\end{array}$ & $\begin{array}{l}6 / 13 \\
46 \cdot 2\end{array}$ \\
\hline
\end{tabular}

range: 59.4 per cent. Similarly, the frequency of AA in the $F_{2}$ generation is $57 \cdot 1$ per cent. The highest frequency was observed in the $B_{1}$ generation and the lowest in the $B_{2}$ generation (70 and 43.3 per cent. respectively).

None of the control rats exhibited any sign of the disease. A different ratio of relative incidence of nodular and oedematous AA was observed in inbred strains as well as in the generations derived. The Table shows that there is a positive correlation between the total frequency of AA and the percentage of its oedematous type. This is true both for inbred strains alone and for derived generations.

Percentiles derived from the total frequency of AA in the strains Lewis and AVN and in the $F_{1}$ generation are presented in the Figure. They represent populations means in the scale of a presumed continuously varying causal mechanism. The means are expressed as deviations from the 'threshold' in terms of their standard deviation. The 'threshold' is taken as zero or the point of origin of the scale. The means can then reach a negative or a positive sign, according to the AA frequency (less than or more than 50 per cent. respectively). The 'threshold' represents a point where a continually varying invisible (or undetermined) scale comes to its visible part (i.e. the point at which the animals show a response). The mean of the Lewis strain is much further removed from the 'threshold' than the mean of the AVN strain. The mean of the $F_{1}$ generation lies not at a midparent value, but is situated nearer to the mean of the resistant strain AVN.

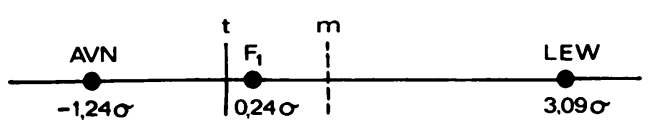

FIG URE Deviations of underlying population means from 'threshold'. $t=$ 'threshold' (zero point); $m=$ midparent value $; \sigma=$ standard deviation

\section{Discussion}

The occurrence of responders in three inbred strains of rats studied is suggestive of a continuous variability of the disease frequency which is in agreement with our previous findings (Zídek and Perlík, 1971). The hypothesis of multifactorial genetic system involvement is thus supported. It is interesting to observe that the variability of such a trait, like its incidence, is so wide, even when studied in genetically homogenous strains. One might expect a complete (or nearly complete) resistance or susceptibility in such populations. The explanation of such situations should be sought in the underlying causal mechanism. The precise mechanism of AA induction has not yet been defined. AA is believed to be the result of a sequence of immunopathological events involving sensitization to antigen, production of immunocompetent cells, cellular hypersensitivity reactions, and release of mediators leading to inflammation (Walz and others, 1971).

The theory of threshold characters presumes the existence of a certain threshold value of a decisive continuously varying factor. Then, if the actual value of this factor is below or above the threshold, animals will be sensitive or resistant (or vice versa). It is presumed that the distribution of deviations caused by environmental sources is normal. When the mean of the decisive underlying factor coincides with the threshold value, half the animals lie below and the other half above the threshold, which gives the frequency of 50 per cent. This situation has probably occurred in the case of the Long Evans strain. The means of the Lewis and AVN strains are far from the threshold (their signs are of course opposite). As the mean of $F_{1}$ hybrids is nearer to the mean of the resistant strain AVN than to the Lewis strain, it indicates an incomplete dominance of the factor influencing the resistance to AA induction.

Unequal ratios of the oedematous and nodular 
types of AA were observed in the three inbred strains used and also in the derived generations. This suggests that the severity of the AA is also influenced by the genetic background. However, the severity of the AA is to be considered cautiously. The degree of oedema varied greatly, but the number of animals responding in this way was not large enough for the severity to be classified precisely, and for the sake of simplicity only two classes have been distinguished. There was a positive correlation between the total frequency of AA and the percentage of the oedematous type. This correlation leads to the hypothesis that identical or similar genetic systems may control the frequency of AA on the one hand and the severity of AA on the other. This may in turn be explained by the theory of threshold characters. It may be presumed that not only the incidence but also the severity is determined by the difference between the threshold and the corresponding value of the pathogenic mechanism.

\section{Summary}

Differences were observed in the frequency of AA in three inbred strains of rats and in the generations derived therefrom. A multifactorial type of inheritance of sensitivity to AA induction, which seems to be of a threshold character, is indicated. It is suggested that both the frequency and the severity of AA are controlled by the same genetic system.

\section{References}

CURrey, H. L. F., (1970) Ann. rheum. Dis., 29, 314 (Adjuvant arthritis in the rat)

FALCONER, D. S. (1960) 'Introduction to Quantitative Genetics', p. 301. Oliver and Boyd, Edinburgh and London

Fisher, R. A., AND YaTES, F. (1943) 'Statistical Tables,' 2nd ed., Oliver and Boyd, Edinburgh and London

Glenn, E. M., AND GraY, J. (1965) Amer. J. vet. Res., 26, 1180 (Adjuvant-induced polyarthritis in rats. Biologic and histologic background)

Newbould, B. B. (1963) Brit. J. Pharmacol., 21, 127 (Chemotherapy of arthritis induced in rats by mycobacterial adjuvant)

Pearson, C. M. (1956) Proc. Soc. exp. Biol. (N.Y.), 91, 95 (Development of arthritis, periarthritis, and periostitis in rats given adjuvants)

Rosenthale, M. E. (1970) Arch. int. Pharmacodyn., 188, 14 (A comparative study of the Lewis and Sprague Dawley rat in adjuvant arthritis)

Swingle, K. F., JaQues, L. W., And Kvam, D. C. (1969) Proc. Soc. exp. Biol. (N. Y.), 132, 608 (Differences in the severity of adjuvant arthritis in four strains of rats)

Walz, D. T., DiMartino, M. J., AND Misher, A. (1971) J. Pharmacol. exp. Ther., 178, 223 (Adjuvant-induced arthritis in rats. II Drug effects on physiologic, biochemical and immunologic parameters)

Winter, C. A., AND Nuss, G. W. (1966) Arthr. and Rheum., 9, 394 (Treatment of adjuvant arthritis in rats with antiinflammatory drugs)

Zídek, Z., AND PerLík, F. (1971) J. Pharm. Pharmacol., 23, 389 (Genetic control of adjuvant-induced arthritis in rats) 